\title{
Long-Term Growth and Remodeling of Regenerated Retino-Collicular Connections in Adult Hamsters
}

\author{
D. A. Carter, ${ }^{a}$ G. M. Bray, and A. J. Aguayo \\ Centre for Research in Neuroscience, The Montreal General Hospital Research Institute and McGill University, Montréal, \\ Québec, Canada H3G 1A4
}

The capacity of regenerating axons for long-term growth and synaptic plasticity was investigated in the visual system of adult hamsters. Four to six and 8-10 months after the eye and the superior colliculus (SC) were linked by a peripheral nerve (PN) graft, the retinal ganglion cell (RGC) axons that had regrown into the SC were examined ultrastructurally. Together with the data from hamsters with similar PN grafts for 2 months (Carter et al., 1989), this study spans most of the life of these animals. The overall findings indicate that (1) the RGC axons extended twice as far into the SC and the number of RGC terminals increased $\mathbf{3 0}$-fold between 2 and 4-6 months. These parameters did not change thereafter. The highest density of regenerated RGC terminals observed in the SC was $11.5 \%$ of controls. (2) The new RGC terminals acquired most of their normal ultrastructural characteristics by 2 months. (3) The mean size of the terminals was larger than in controls but decreased gradually, and there was a small increase in the size of the regenerated synapses. (4) At all times, the RGC terminals remained confined to the layers of the SC that normally receive retinal inputs, and their synapses were formed in normal proportions with the dendritic shafts and spines of SC neurons.

Thus, there is a protracted long-term growth and remodeling of the RGC axons that have regenerated into the SC of these adult mammals. The preservation of specific laminar distributions and proportions of postsynaptic neuronal domains contacted by the reformed terminals suggest that the extension of these central axons into the SC is not random but is persistently influenced by local interactions involved in the recognition of appropriate targets.

[Key words: regeneration, retinal ganglion cell, superior colliculus, synapse]

Injured retinal ganglion cell (RGC) axons that regenerate along peripheral nerve $(\mathrm{PN})$ grafts in adult rodents can grow into the superior colliculus (SC) and form synapses (Carter et al., 1989;

\footnotetext{
Received Jan. 20, 1993; revised July 12, 1993; accepted July 22, 1993.

The technical assistance of M. David, J. Laganière, J. Trecarten, and W. Wilcox is gratefully acknowledged. We thank Dr. J. Hanley, Dr. S. Suissa, and J. Adam for assistance with the statistical analysis. D.A.C. was supported by a Medical Research Council fellowship. The Medical Research Council of Canada and the Multiple Sclerosis Society of Canada provided financial support. The laboratory in which these studies were carried out is part of the Canadian Network for the Study of Neural Regeneration and Functional Recovery.

Correspondence should be addressed to Dr. A. J. Aguayo, Centre for Research in Neuroscience, Montreal General Hospital, 1650 Cedar Avenue, Montréal, Québec, Canada H3G 1 A4.

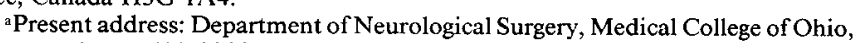
Toledo, OH 43699-0008.
}

Copyright $@ 1994$ Society for Neuroscience $0270-6474 / 94 / 140590-09 \$ 05.00 / 0$
Vidal-Sanz et al., 1991) that transynaptically activate SC neurons in response to light (Keirstead et al., 1989). It is not known, however, if these regenerating central axons continue to extend and differentiate within the CNS for prolonged periods of time. The documentation of such changes would have implications for the recovery of function after CNS injury and for the development of appropriate strategies to enhance CNS reinnervation, particularly if both regrowth and synaptogenesis remain confined to the appropriate regions of the SC.

The present anatomical study documents changes in the penetration, number, and ultrastructure of RGC axon terminals formed in the SC 4-6 and 8-10 months after the insertion of PN grafts into the SC. These features are compared with previous results from a similar investigation carried out 2 months after the reinnervation of the SC by regenerating $\mathrm{RGC}$ axons (Carter et al., 1989).

Our findings demonstrate that while the main characteristics of individual terminals and synapses are rapidly acquired when the RGC axons penetrate the SC, there is a lengthy but finite period of continuous axonal growth characterized by the formation of many new terminals and gradual changes in terminal morphology. Such axonal regrowth and synaptogenesis occur exclusively within the normal retinorecipient layers of the SC and upon appropriate postsynaptic neuronal domains.

\section{Materials and Methods}

In 14 adult female hamsters (Mesocricetus auratus, 90-120 d old), the right optic nerve (ON) was transected immediately behind the eye, avoiding injury to the blood vessels that supply the retina. An excised segment of autologous peroneal nerve $2-3 \mathrm{~cm}$ in length was sutured to the ocular stump of the transected ON. Five to seven weeks later, the distal end of the graft was separated into two strands and inserted superficially into the lateral aspect of the SC, exposed on the ipsilateral side by resecting part of the overlying occipital lobe (Carter et al., 1989). After 2-3 weeks, the left ON was transected to assure that all retinal inputs to the SC were interrupted. Four to six $(n=7)$ or $8-10(n=7)$ months after PN graft insertion, $3 \mu \mathrm{l}$ of $30 \%$ horseradish peroxidase (HRP; Boehringer Mannheim) was injected into the right eye. For all procedures, the hamsters were anesthetized with intraperitoneal pentobarbital $(35 \mathrm{mg} / \mathrm{kg})$

\section{Tissue processing}

Two days after HRP injection, the animals were perfused with $2.5 \%$ glutaraldehyde and $0.5 \%$ formaldehyde in $0.1 \mathrm{~m}$ phosphate buffer. Transverse serial sections of the midbrain were cut at 50-70 $\mu \mathrm{m}$ with a vibrating microtome and processed for HRP histochemistry to visualize the terminal portions of the regenerated retinal axons by light and electron microscopy (Carter et al., 1989, 1991a). Sections were subsequently stained with $1 \%$ osmium tetroxide, flat-embedded in epoxy resin, and examined by light microscopy. SC areas showing HRP reaction product were drawn by camera lucida. 


\section{Ultrastructural analysis}

Sections from the four animals that showed the most extensive HRP labeling by light microscopy in the 4-6 month (HRM 129, 131, 152, $175)$ and the 8-10 month (HRL 130, 151, 155, 177) groups were processed for electron microscopy (EM). To sample axon terminals throughout the labeled region, we examined single ultrathin sections from every fourth $50-70-\mu \mathrm{m}$-thick section (i.e., separated by approximately 240 $\mu \mathrm{m})$. In these sections, all labeled axon terminals, characterized by their content of clear synaptic vesicles and HRP reaction product, were photographed and their ultrastructural features analyzed in electron micrographs printed at $35,000 \times$. Most terminal bulbs were delineated by their plasma membranes. Sometimes the plane of sectioning included the junction between the preterminal axon and the terminal bulb. This junction usually involved less that $25 \%$ of the terminal circumference. The perimeters of such terminals were estimated by drawing a line between the preterminal axon and the terminal bulb. En passant synapses, which were infrequently observed, were also photographed but were not included in the analysis of terminal bulbs.

For comparisons of the maximum densities of RGC terminals in control and regenerated animals, the numbers of HRP-labeled terminals were counted in well-labeled areas of the SCs of two PN-grafted (HRM129, HRL.151) hamsters and in comparable parts of the SCs of two control (C11, C12) animals.

For each of the HRP-labeled terminals, the area, perimeter, index of circularity, and synapse lengths were calculated from the electron micrographs with the aid of an IBAS I tablet digitizer. Synapses were categorized as asymmetric or symmetric according to standard criteria (Jones, 1983); obliquely sectioned synapses were eliminated if the synaptic cleft could not be visualized. Ratios of the number of synapses and the length of the postsynaptic densities to the terminal perimeter were calculated for each terminal (Carter et al., 1991a).

Because retino-SC terminals in the upper stratum griseum superficiale (SGS) are smaller than those located in the lower one-third of the SGS or in the stratum opticum (SO) and stratum griseum intermedium (SGI) in normal hamsters (Carter et al., 1991a), we also compared regenerated RGC axon terminals in the upper SGS with those in the SO. Precise identification of SC laminae was often difficult near the site of graft insertion but in two of the 4-6 month animals (HRM129, HRM131) and two of the 8-10 month animals (HRL151, HRL177), regenerated terminals were identified at least $250 \mu \mathrm{m}$ from the graft tip: 141 in the superficial one-quarter of the SGS and 117 in the SO, identified by the bundles of corticotectal myelinaled fibers (Ramirez et al., 1990) that persisted when most fibers of optic nerve origin had degenerated. For comparison with normal RGC terminals, we used 251 upper SGS terminals from the most superficial $110 \mu \mathrm{m}$ of the SC and $147 \mathrm{SO}$ terminals located more than $275 \mu \mathrm{m}$ below the surface of the contralateral SC from previously reported control animals (Carter et al., 1991a).

The postsynaptic structures contacted by regenerated synapses were classified as spine-like processes, dendritic shafts, somata, or undefined profiles. To distinguish between dendritic shafts and spines, we used the criteria of Jones (1983); shafts tended to be larger and exhibited prominent neurofilaments and microtubules, while spines were smaller and containcd amorphous matcrial and occasional mitochondria. For purposes of classification, the vesicle-filled postsynaptic profiles that are prominent in the SC (Lund, 1969; Valverde, 1973) were designated as "spine-like" if they did not show neurofilaments or microtubules. We also calculated the numbers of the postsynaptic targets that contained vesicles (three or more).

Because similar ratios of spine-like structures and dendritic shafts were contacted by the regenerated and control terminals (see Results and Carter et al., 1989), we determined the relative prevalence of these structures after the $\mathrm{SC}$ was denervated by transection of the contralateral ON. Six EM montages from the upper SGS and six of the SO were photographed from two of the ultrastructurally studied animals with PN grafts. Each montage was taken from a region of the SC that was more than $1.5 \mathrm{~mm}$ from the tip of the graft. The perimeters of all dendritic shafts and spine-like structures were measured and the ratios of these measurements calculated for each $137 \mu \mathrm{m}^{2}$ montage.

Controls. Regenerated axon terminals observed in coronal sections of the animals surviving 4-6 months ( $n=4$ animals, 580 terminals) and $8-10$ months ( $n=4$ animals, 470 terminals) were compared with each other, and with 698 control terminals similarly identified and analyzed in four intact hamsters (Carter et al., 1991a) and 758 regenerated terminals ( $n=4$ animals) 2 months after PN graft insertion
(Carter et al., 1989). To assess possible changes in retino-SC terminal characteristics associated with aging of these animals, four normal female hamsters, aged 14-16 months, received intraocular injections of $\mathrm{HRP}$ and retino-SC terminals were examined in columns of the contralateral and ipsilateral SCs as previously described (Carter et al., 1989).

As a validation of the method of identifying regenerated $\mathrm{RGC}$ axon terminals and comparing them to controls, we observed the following. (1) There was no labeling in the SC after retroorbital injections of HRP. This finding, in conjunction with previous anatomical observations (Vidal-Sanz et al., 1987, 1991; Carter et al., 1989) and the demonstration that visual stimuli can transynaptically activate SC neurons in similarly prepared hamsters (Keirstead et al., 1989), supports the contention that the HRP-labeled profiles seen in the SC after intravitreal injection arose from RGCs. (2) Similar ranges of regenerated axon terminal areas were obtained in sagittal and coronal sections of the SC (data not shown), indicating that the dimensions of the regenerated terminals in coronal sections adequately reflect their size and shape.

\section{Statistical analyses}

Axon terminal areas and perimeters, indices of circularity, contacts/ terminal perimeter, synapse lengths, and synapse lengths/terminal perimeter for the experimental and control groups were compared by an analysis of variance, using a nested design for unbalanced data by comparing the ratios of the type III mean square for the groups to the mean square for animals within each group (SAS Institute, Inc., Cary, NC). For the comparisons among four groups of animals (e.g., controls, and the 2, 4-6, and 8-10 month PN-grafted animals), there were 3 and 12 degrees of freedom. When a significant main effect was observed, post hoc Tukey tests were performed to determine the source of the significant difference.

Contacts per terminal in the control, 2, 4-6, and 8-10 month animals were compared by analyzing the numbers of terminals with zero, one, two, or more than two contacts with a nonparametric test for ranked data (Kruskal-Wallis). The proportion of regeneratcd and control tcrminals that synapsed with vesicle-containing postsynaptic processes and spine-like profiles were compared with an analysis of variance and post hoc Tukey tests, using each animal as the unit of analysis.

\section{Results}

\section{Distribution of regenerated $R G C$ axons}

In hamsters with $\mathrm{PN}$ grafts connecting the retina and the $\mathrm{SC}$ for 4-6 or 8-10 months, punctate HRP reaction product was observed by light microscopy up to $1 \mathrm{~mm}$ in the coronal plane and $500 \mu \mathrm{m}$ rostrally and caudally beyond the tip of the graft (Fig. 1). The average maximal coronal extension of regenerated axons from the tip of the graft into the SC at 4-6 months (720 $\pm 57 \mu \mathrm{m})$ and at $8-10$ months $(718 \pm 71 \mu \mathrm{m})$ was greater than the maximal axonal growth at 2 months $(362+32 \mu \mathrm{m})$ (Fig. 2 ). The increased distance of the terminals of these axons from the end of the grafts was likely due to axonal growth rather than SC shrinkage; the mediolateral dimensions of the SCs were less than normal at 2 months but did not change significantly between 2 and 4 months after ON transection (Carter, 1991).

Most regenerated RGC axon terminals were observed in the SGS and SO. In addition, there were small numbers of regenerated RGC axon terminals in the upper SGI, which in control hamsters receives a minor part $(<2 \%)$ of the retino-SC projection (Carter et al., 1991a).

\section{Appearance and number of regenerated terminals}

Regenerated RGC terminals (Fig. 3) showed the spherical vesicles, pale mitochondria, and asymmetric synaptic contacts characteristic of control and 2 month regenerated retino-SC terminals (Carter et al., 1989, 1991a). However, fewer of the large labeled terminals previously observed 2 months after PN graft insertion (Carter et al., 1989) were seen in the SCs of animals surviving for 4-6 or 8-10 months.

The zone of HRP labeling around the end of each graft was 


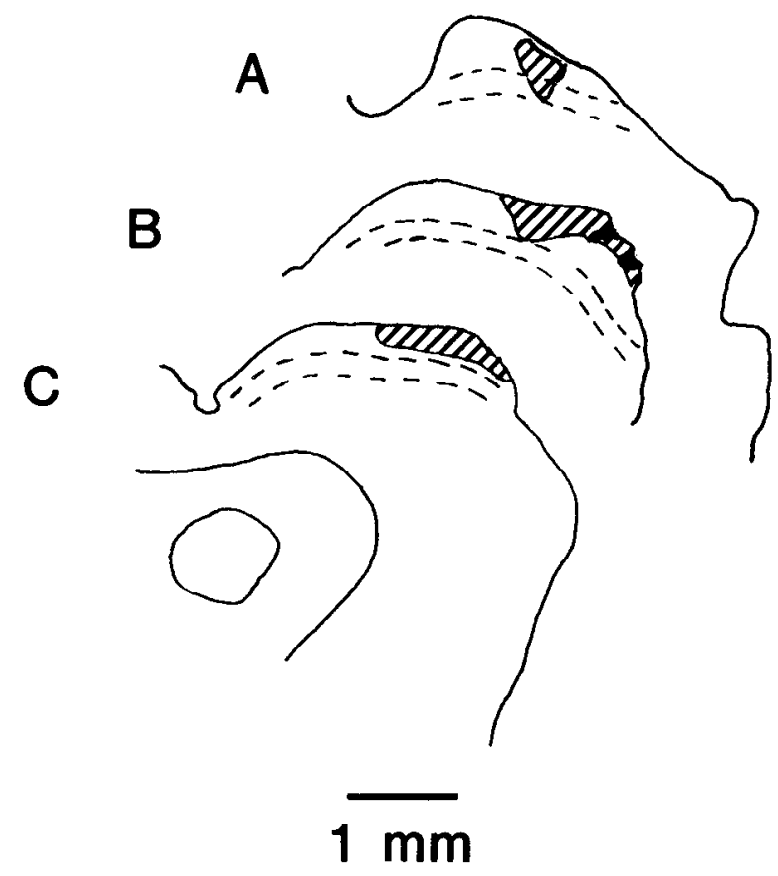

Figure 1. Distribution of HRP-labeled RGC axon terminals (hatched) 8 months after insertion of a PN graft into the lateral SC: camera lucida drawings from three transverse midbrain sections separated by 400 $500 \mu \mathrm{m}$. The solid areas in $B$ represent the end of the graft. The hatched areas delineate the extent of punctate HRP labeling identified by light microscopy and studied by EM. The broken lines indicate the borders of the stratum opticum. Most of the HRP labeling is located above the stratum opticum in the stratum griseum superficiale. Scale bar, $1 \mathrm{~mm}$.

sampled by examining ultrathin sections from every fourth 50$70-\mu \mathrm{m}$-thick section until no labeled terminals were detected. In these single ultrathin sections separated by approximately $240 \mu \mathrm{m}$, there were 68-209 labeled terminals per animal. If the zones of HRP labeling had been sampled at $6 \mu \mathrm{m}$ intervals, as was done in our earlier study (Carter ct al., 1989), only a fcw terminals would have been examined more than once because the maximum diameter of more than $99 \%$ of the regenerated RGC terminals was less than $6 \mu \mathrm{m}$. Furthermore, approximately 40 times as many labeled terminals would have been expected. Therefore, to estimate the total number of regenerated RGC axon terminals per animal, the actual number of HRP-labeled terminals counted in the sections at $240 \mu \mathrm{m}$ intervals was multiplied by 40 . This calculation yielded total numbers of HRPlabeled terminals per animal of $5800 \pm 1171$ at 4-6 months with no significant change at 8-10 months, when the mean number was $4720 \pm 760$ (Fig. 2). Such calculations probably underestimate the actual incidence of regenerated terminals because (1) some regenerated terminals smaller than $6 \mu \mathrm{m}$ would not be sampled, and (2) all regenerated terminals might not be labeled in single ultrathin sections by the discontinuous HRP reaction product label (Carter et al., 1991a).

The estimates of the total numbers of regenerated RGC axon terminals were approximately 30 -fold greater than the estimates at 2 months, when there were $20-423$ (mean \pm SEM, $189 \pm$ 92; Carter et al., 1989) regenerated terminals per animal (Fig. 2). Such comparisons with the 2 month group of animals were considered to be valid because there were no significant changes in the indices of circularity among the three groups of terminals (Table 1). Furthermore, the decrease in the mean areas of the
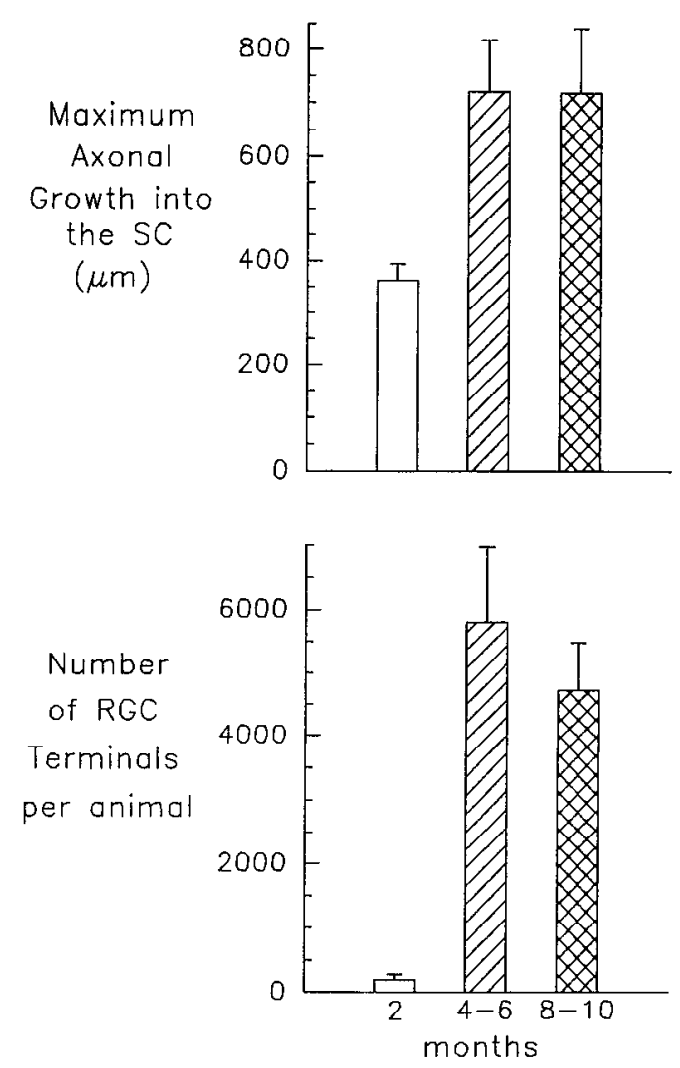

Figure 2. Growth of regenerated RGC axons and terminals in the SC 2, 4-6, and 8-10 months after a PN graft containing regenerating RGC axons was inserted into the midbrain in adult hamsters. Data for 2 months are from Carter et al. (1989). Top, Maximum axon growth determined by measuring the greatest distance that HRP reaction product was observed from the end of the graft in the midbrain. Bottom, Numbers of regenerated RGC terminals per animal estimated as described in Results. Means $\pm \mathrm{SEM} ; n=4$ animals per group.

regenerated terminals between 2 months and 8-10 months may havc led to underestimates of the numbers of terminals in the 4-6 and 8-10 month animals.

The numbers of terminals per unit area were calculated for regions of two PN-grafted SCs (HRM129, HRL151) where the incidence of HRP-labeled terminals appeared to be greatest and compared with similar regions of the SCs from two control animals $(\mathrm{C} 11, \mathrm{C} 12)$. Eleven regenerated terminals were identified in $16,500 \mu \mathrm{m}^{2}$ of such areas of the SCs from the experimental animals, while there were 91 labeled terminals in $15,730 \mu \mathrm{m}^{2}$ of comparable parts of the SCs from the control animals. Assuming that HRP was similarly transported in the experimental and control RGCs, the density of the regenerated RGC terminals represented $11.5 \%$ of the control RGC terminals.

\section{Axon terminal size}

The mean areas of terminals (Fig. 4) in all retinorecipient laminae of the SC at $4-6$ months $\left(1.72 \pm 0.06 \mu \mathrm{m}^{2}\right)$ and at $8-10$ months $\left(1.59 \pm 0.05 \mu \mathrm{m}^{2}\right)$ were not significantly different $(p>$ 0.05 ) from each other but were less than the mean areas (1.96 $\pm 0.09 \mu \mathrm{m}^{2}$ ) of regenerated terminals 2 months after PN graft placement (Carter et al., 1989). However, the terminal areas at 4-6 and 8-10 months remained significantly greater than those of controls $\left(0.97 \pm 0.02 \mu \mathrm{m}^{2}\right)$ (Fig. 4). Axon terminal perimeters showed similar differences (data not shown). Normal age-related changes are unlikely to explain these changes in terminal size 

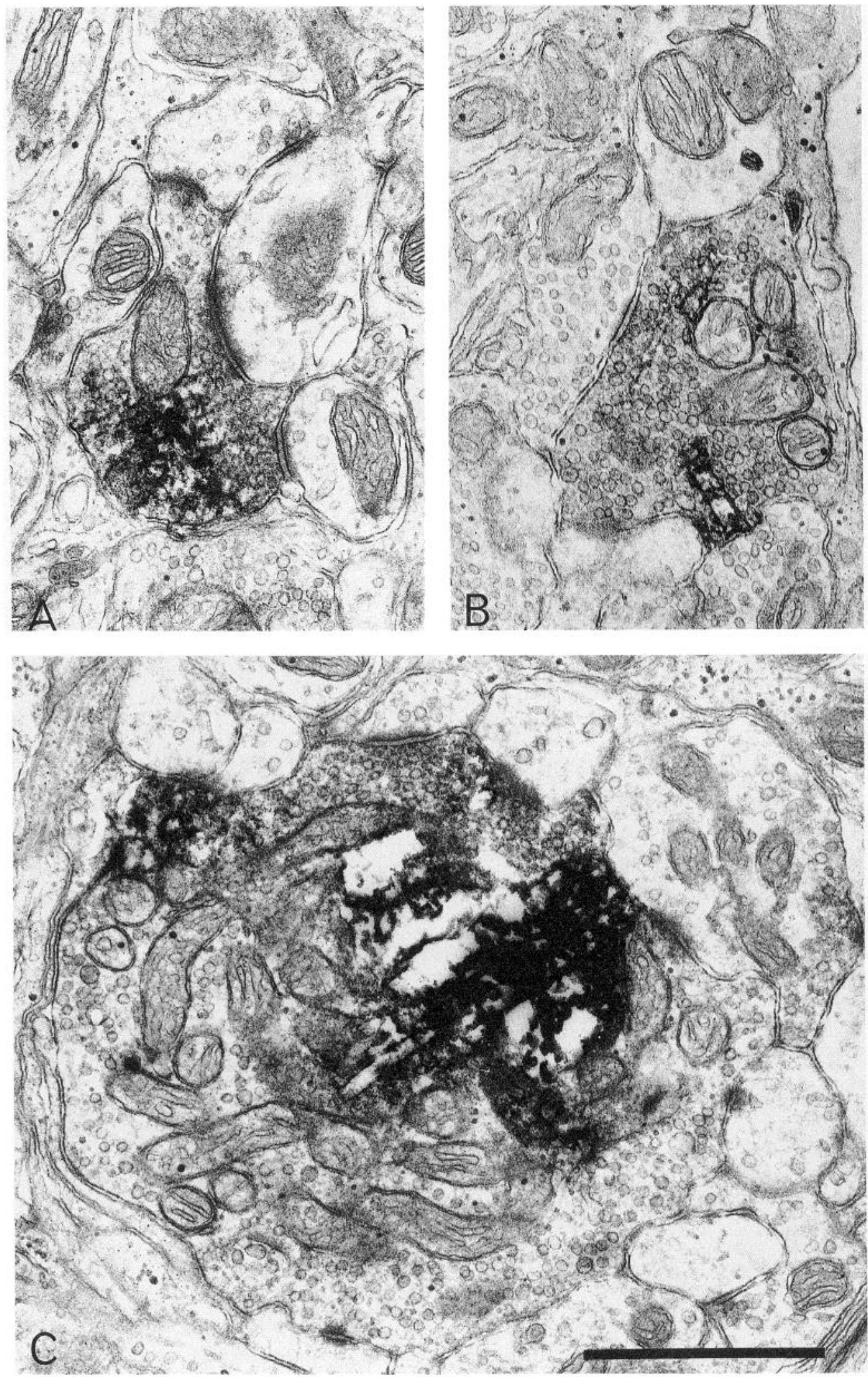

Figure 3. Regenerated RGC axon terminals in the SC. The terminals, labeled with HRP that had been injected intravitreally, contain crystalline reaction product, clear synaptic vesicles, and pale mitochondria. $A$, A small terminal in the SGS of an animal surviving 5 months after PN graft insertion forms asymmetric synapses with spine-like profiles (at top and bottom) and with an undefined profile (middle right). The upper profile synapses with the middle postsynaptic structure. $B$, An HRP-labeled retino-SC terminal in the SGS of an animal 9 months after graft insertion forms an asymmetric synapse with a vesicle-filled postsynaptic profile. $C, \mathrm{~A}$ large terminal in the SO of an animal that survived for 5 months forms asymmetric synapses with spine-like profiles (at top and bottom) and with a dendritic shaft (upper right). Scale bar, $1 \mu \mathrm{m}$.

over time; control experiments revealed no significant difference in retino-SC terminal size in hamsters of comparable ages (Carter, 1991).

Regenerated terminals in the upper and lower parts of the retinorecipient SC were also compared in the four grafted ani- mals in which it was possible to distinguish SC laminae near the graft termination. As in normal hamsters (Carter et al., 1991a), regenerated terminals in the SO were significantly larger than those in the upper SGS (Fig. 5). Compared in analogous parts of control and PN-grafted SCs, the areas of regenerated 
Table 1. Regenerated and control retino-SC synapses

\begin{tabular}{|c|c|c|c|c|}
\hline & Control $^{a}$ & 2 months ${ }^{b}$ & 4-6 months & $8-10$ months \\
\hline Animals $(n)$ & 4 & 4 & 4 & 4 \\
\hline Terminals ( $n$ ) & 698 & 758 & 580 & 470 \\
\hline Area $^{c}$ & $0.97,0.02$ & $1.96,0.09^{g}$ & $1.72,0.06^{g, h}$ & $1.59,0.05^{g}$ \\
\hline Circularity index ${ }^{c}$ & $0.64,0.02$ & $0.61,0.04$ & $0.65,0.05$ & $0.62,0.03$ \\
\hline Synapses $(n)$ & 471 & 901 & 587 & 490 \\
\hline Asymmetric (\%) & 97.4 & 98.8 & 100 & 99.8 \\
\hline \multicolumn{5}{|l|}{ Nurıber/terminal (\%) } \\
\hline 0 & 47.9 & $34.5^{\prime \prime}$ & $37.9^{e}$ & $34.6^{e}$ \\
\hline 1 & 39.4 & 37.4 & 39.5 & 42.3 \\
\hline 2 & 10.7 & 16.7 & 16.7 & 14.0 \\
\hline$>2$ & 2.0 & 11.4 & 5.9 & 9.1 \\
\hline Mean & 0.7 & 1.2 & 0.9 & 1.0 \\
\hline \multicolumn{5}{|l|}{ Number $/ 10 \mu \mathrm{m}$ terminal } \\
\hline Length $(\mu \mathrm{m})^{c, d f}$ & $0.31,0.01$ & $0.38,0.0 \mathrm{l}^{g}$ & $0.35,0.01^{g, h}$ & $0.37,0.01^{g, h}$ \\
\hline \multicolumn{5}{|l|}{ Length $/ 10 \mu \mathrm{m}$ terminal } \\
\hline \multicolumn{5}{|l|}{ Postsynaptic structures } \\
\hline \multicolumn{5}{|l|}{ Distribution (\%) } \\
\hline Somata & 0 & 0.1 & 0 & 0 \\
\hline \multicolumn{5}{|l|}{ Dendrites } \\
\hline spine-like & $60.9,2.5$ & $60.8,1.6$ & $64.7,2.1$ & $61.4,2.6$ \\
\hline Shafts & 33.1 & 33.6 & 34.7 & 34.2 \\
\hline Undefined & 6.0 & 5.6 & 7.6 & 10.2 \\
\hline $\begin{array}{l}\text { a From Carter et al. (1991a } \\
\text { " From Carter et al. (1989) } \\
\text { " Mean, SEM. } \\
{ }^{d} \text { Determined for } 352 \text { cont } \\
\text { " Distribution significantly } \\
\text { 'Significant main effect, } p \\
{ }^{8} \text { Significantly different fror } \\
\text { "Significantly different fror } \\
\text { 'Main effect not significan }\end{array}$ & $\begin{array}{l}475 \text {, and } 403 \\
\text { control, } p< \\
<0.01 \text {. } \\
\text { alue for regen }\end{array}$ & rated synapses. & & \\
\hline
\end{tabular}

and control terminals in the upper SGS were not significantly different. In contrast, regenerated terminals in the $\mathrm{SO}$ remained significantly larger than those in the control SO (Fig. 5).

\section{Characteristics of the re-formed synapses}

Approximately $50 \%$ of the control RGC terminals and $65 \%$ of the regenerated terminals showed synaptic specializations in single EM sections (Figs. 3,6). The distributions of the number of synapses per terminal (Fig. 6) were significantly different for the regenerated and control terminals $(p<0.01$, Kruskal-Wallis test for ranked data). In addition, the mean numbers of synapses per $10 \mu \mathrm{m}$ terminal perimeter (synaptic density) were slightly greater than normal at all times studied, although only statistically significant at $8-10$ months when the increase was $27 \%$ (Fig. 4). These increases in synapse numbers probably reflcctcd the greater incidence of multiple synapses for the regenerated terminals; similar proportions of the regenerated and control terminals had one or two synapses per terminal, while more than two synapses were more common in the regenerated terminals (Fig. 6). The late changes in the regenerated synapses were not likely attributable to age because such synaptic measurements were stable in aged control animals (Carter, 1991).

The mean lengths of the postsynaptic densities of the regen- erated synapses grouped for all laminae were increased by $13 \%$ at 4-6 months and by $19 \%$ at 8-10 months (Fig. 4, Table 1). However, the ratios of synapse length per $10 \mu \mathrm{m}$ terminal perimeter were, respectively, 33\% and 69\% higher (Fig. 4). When compared in different laminae of the SC, the mean synapse lengths and synapse lengths per $10 \mu \mathrm{m}$ terminal perimeter were significantly greater than normal in both the upper SGS and the SO (Fig. 5).

\section{Characteristics of the postsynaptic targets in the SC}

Most of the structures contacted by regenerated retino-SC terminals could be defined as dendritic shafts, spines, or vesiclecontaining profiles (Lund, 1969; Valverde, 1973). At each time studied, the proportions of synapses with spine-like structures were not significantly different for regenerated and control terminals (Table 1). To determine if this pattern was influenced hy the availability of dendritic shafts and spines, we measured the ratios of spine/shaft membranes in electron micrographs of denervated segments of SC. In contrast to the spine:shaft ratios, which were 60:33 (1.8) for the control and regenerated SC regions, the ratios of spine:shaft membranes in the denervated SCs were $20: 62(0.32)$. The approximate reversal of this ratio suggests that the regenerated terminals did not form synapses with post- 

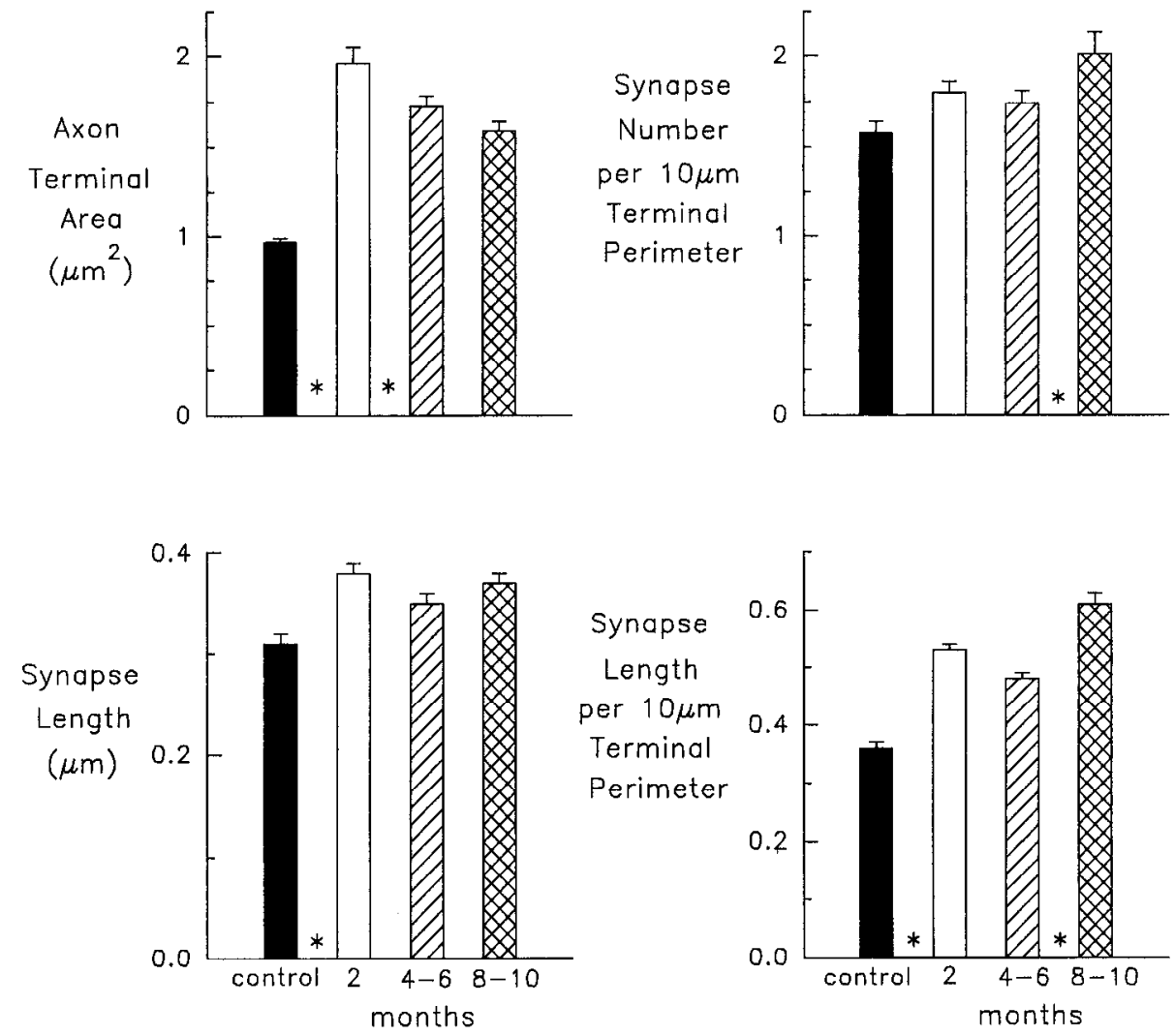

Figure 4. Changes in regenerated RGC terminals and synapses in the SC 2, 46 , and 8-10 months after PN grafting. Data for 2 months are from Carter et al. (1989); control data are from Carter et al. (1991a). Axon terminals gradually decreased in size, ratios of synapse number and synapse length to terminal perimeter increased, and the mean synapse lengths remained greater than normal. Means \pm SEM; $n=4$ animals per group. ${ }^{*}$, significant difference $(p<0.01)$ between adjacent bars.
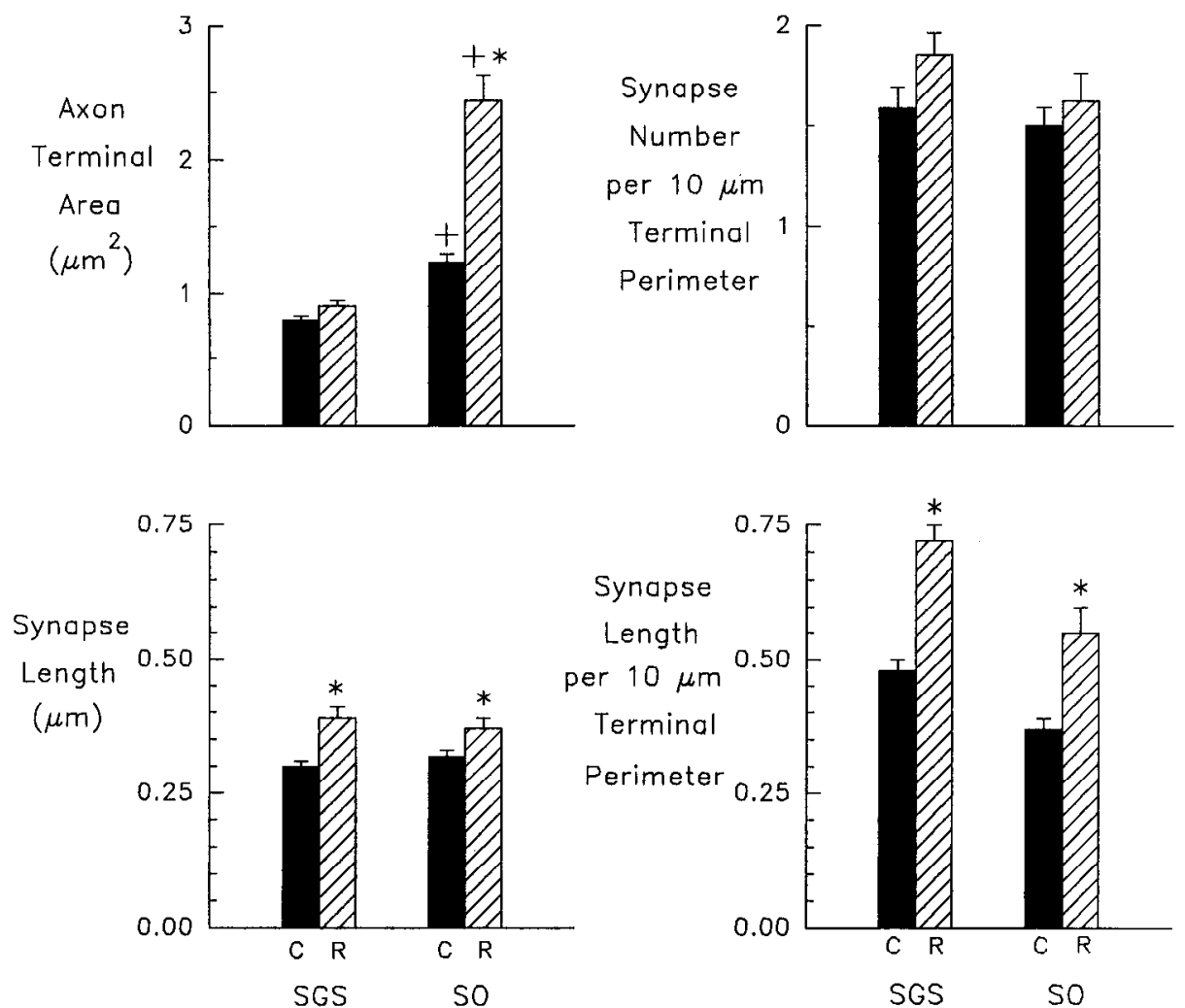

Figure 5. Characteristics of regenerated $(R)$ and control $(C)$ RGC terminals and synapses in the superficial gray layer of the SC $(S G S)$ and in the stratum opticum $(S O)$. Control data from four intact animals are from Carter et al. (1991a); data for regenerated terminals are pooled from two animals with PN grafts for $4-6$ months and two with grafts for 8-10 months. ${ }^{*}$, significantly different from control; $p<0.01$; + , significantly different from terminals in the upper SGS, $p<0.01$. 


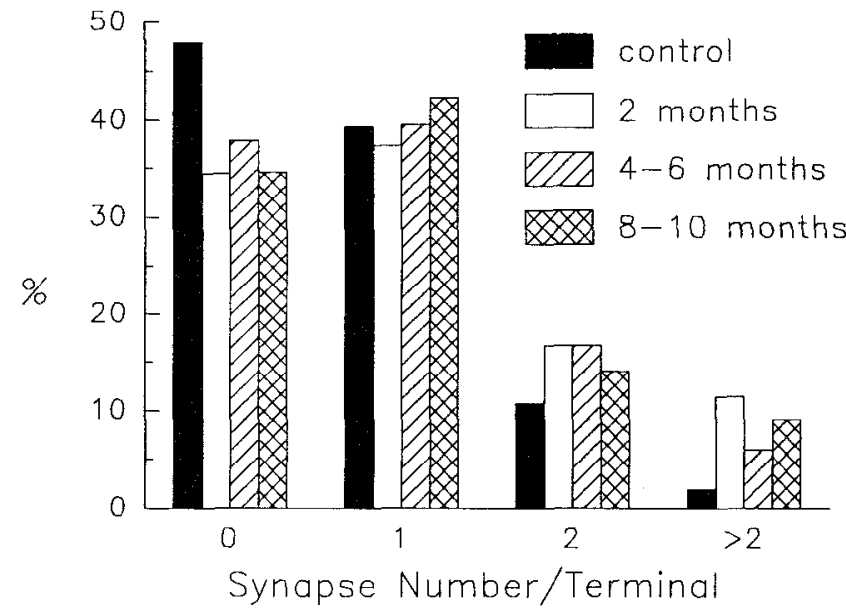

Figure 6. Proportions of RGC terminals with zero, one, two, or more than two synapses in single electron micrographs. Data for 2 months are from Carter et al. (1989); control data are from Carter et al., (1991a) For terminals making one or two contacts, the patterns of regenerated terminals ( 2 months, open bars; $4-6$ months, hatched bars; $8-10$ months, cross-hatched bars) were similar to those of controls (solid bars). The small proportion of terminals that formed more than two synapses was increased for the regenerated terminals.

synaptic surfaces at random and is consistent with the existence of specific interactions between pre- and postsynaptic elements capable of influencing neuronal recognition or differentiation.

In control animals, $29.5 \%$ of synapses contacted vesicle-containing postsynaptic processes, many of which are GABAergic neurons (Streit et al., 1978; Mize et al., 1982; Houser et al., 1983). This proportion, which was increased to $48 \%$ at 2 months (Carter et al., 1989) and to 39\% 4-6 months after PN graft insertion, returned to normal by $8-10$ months.

\section{Discussion}

The results of this study of regenerated $\mathrm{RGC}$ axon terminals and synapses at 4-6 and 8-10 months after connecting the eye and the SC with a PN graft should be considered with our previous analysis of similarly treated hamsters examined at 2 months (Carter ct al., 1989).

\section{Regrowth of RGC axons into the SC}

The 2-fold increase in the lengths of the regenerated axons in the $\mathrm{SC}$ and the 30 -fold increase in the estimated numbers of terminals suggest that for a period of 4-6 months, the putative influences that promote a gradual axonal extension and the formation of new terminals predominated over those that inhibited their growth in the injured SC. Denervation of the superficial $\mathrm{SC}$ may have facilitated the regrowth of the RGC axons. Such an effect has been demonstrated in muscle and other targets (for review, see Purves and Lichtman, 1985). Furthermore, regenerating $\mathrm{RGC}$ axons extended farther into the cerebellar cortex if the target was partially denervated (Zwimpfer et al., 1992). Axonal regrowth into the $\mathrm{SC}$ could also have been influenced by the expression of molecules originating in the grafted PN segment (Heumann et al., 1987; Meyer et al., 1992) or by temporary local changes in the injured CNS (David et al., 1990; D. B. Clarke, G. M. Bray, and A. J. Aguayo, unpublished observations).

Several influences may have curtailed the growth of regenerating $\mathrm{RGC}$ axons into the SC. Growth-inhibiting molecules associated with oligodendrocytes and myelin in the mammalian
CNS appear to limit the extension of RGC axons in the SCs of neonatal hamsters (Kapfhammer et al., 1992). However, such effects may be minimal in the superficial SC where there are few myelinated fibers, particularly after degeneration of all the myelinated RGC axons interrupted in the ON. Synapse formation with SC neurons near the end of the graft may have also prevented further regrowth into the SC. Such an effect on axonal extension has been proposed after spinal cord lesions (Bernstein and Bernstein, 1971; Duffy et al., 1992). The formation of large numbers of synapse-bearing terminals during the first 4 months after the PN grafts are inserted into the $\mathrm{SC}$, and the observation that the RGC axons branched and formed terminals close to the end of the PN graft (Carter et al., 1991b) are consistent with such an explanation. Finally, it is possible that the postulated influences from the PN graft may eventually become ineffective, cither because of the diminished production of the putative trophic factors by non-neuronal cells or because of changes in the expression of neuronal receptors for these molecules.

\section{Formation of regenerated $R G C$ axon terminals and synapses}

The maximum densities of regenerated RGC terminals in the $\mathrm{SC}$ remained reduced at $11.5 \%$ in spite of the 30 -fold increase in RGC terminals and synapses between 2 and 4-6 months and the formation of normal numbers of terminal boutons by many regenerated RGC axons (Carter et al., 1991b). The survival of less than $10 \%$ of the RGC population after ON transection and PN grafting (Villegas-Pérez et al., 1988) undoubtedly contributed to this hypoinnervation of the SC by RGC axons. It is also possible that soon after $\mathrm{ON}$ section, the $\mathrm{SC}$ neurons deprived of their retinal inputs were reinnervated by "reactive synaptogenesis" from nonretinal afferents and intrinsic SC neurons (Houser et al., 1983). Such local responses may have reduced the number of synaptic sites available at the time of when the regenerating $\mathrm{RGC}$ axons arrive in the $\mathrm{SC}$.

\section{Survival of regenerated $R G C S$}

The persistence of the regenerated RGC axons and terminal boutons in the SC between 4-6 and 8-10 months, as well as the presence of regenerated retino-SC terminals in rats after 16-18 months (Vidal-Sanz et al., 1991), suggests that the restoration of retino-SC contacts provides trophic support needed for $\mathrm{RGC}$ survival. It is also possible that the functional activity of these neurons (Keirstead et al., 1989), in turn, contributed to the differentiation of their terminals, a phenomenon that has been described during development (Kalil et al., 1986).

\section{Prolonged remodeling of regenerated $R G C$ axon terminals and synapses}

Many of the morphometric differences between the regenerated and control terminals and synapses, which were present at 2 months (Carter et al., 1989), changed toward normal over the 8-10 months of the present study. However, terminal areas and synapse lengths remained enlarged and the ratios of synapse length to terminal perimeter actually increased.

Axon terminal areas. In rats, in which it was possible to study regenerated retino-SC terminals after longer survival times, the mean terminal areas were normal at 16-18 months (Vidal-Sanz et al., 1991). The determinants of axon terminal size during development or regeneration are not known. However, trophic molecules may play a role in the postinjury remodeling of axon terminals in the CNS (Garofalo et al., 1992). Interactions that depend on the location of the regenerated axon terminals may 
also affect their size. When regenerating $\mathrm{RGC}$ axons were guided to the cerebellum (Zwimpfer et al., 1992), their terminals remained large for the entire period studied (up to 9 months). Thus, the finding of abnormally large terminals in the SO and terminals of normal size in the SGS may indicate that a greater proportion of the terminals in the upper SC (SGS) had reached their appropriate targets.

Synapse length. The average length of the synaptic densities formed by the regenerated RGC terminals was greater than normal at all times studied. In goldfish, regenerating retinotectal terminals form synaptic contacts that are initially longer than normal but decrease to normal by 4 months (Murray and Edwards, 1982; Radel and Yoon, 1985). This change may be influenced by the survival of most RGCs (Murray et al., 1982) and the restoration of normal numbers of retinotectal terminals in this species (Hayes and Meyer, 1988). The persistent increases in synapse length we observed in these hamsters may compensate for the decreased number of RGCs available to regrow into the SC (Villegas-Pérez et al., 1988). Similar increases in synapse length and number per terminal have previously been demonstrated as a result of sprouting into partially denervated areas of the CNS (Raisman, 1969; Sotelo, 1975; Matthews et al., 1976; Hillman and Chen, 1985; Murray et al., 1987; Steward et al. 1988).

The proportion of postsynaptic structures that contained synaptic vesicles was greater than normal at 2 and 4-6 months, returning to control values at $8-10$ months. Many of these vesicle-containing profiles are thought to represent dendrites of intrinsic GABAergic neurons (Mize et al., 1982; Houser et al., 1983). The decrease in the proportion of these neuronal profiles that are contacted by the regenerated RGC terminals may be an example of protracted changes that involve shifting of terminal contacts or a change in the phenotypic expression of the postsynaptic cells.

The present study of re-formed connections in the injured CNS encompassed most of the hamster's life-span. The results suggest that the formation and modification of regenerated synapses and their targets occur over several months and that these changes follow different patterns and schedules. Other lines of evidence support this hypothesis. In goldfish, regenerated retinotectal axon terminals took 12-16 months to return to their normal sizc (Radel and Yoon, 1985). Synaptogencsis has also been studied in adult mammals after partial denervation or following the transplantation of fetal neurons. For example, reactive synaptogenesis plateaued in the partially denervated septal nuclei by 1 month after fimbria-fornix interruption (Raisman, 1969; Raisman and Field, 1973). However, axons from grafts of fetal entorhinal cortex grew into the distal part of the denervated hippocampus for up 106 months (Gibbs et al., 1985). Functional effects of fetal grafts may take 6-9 months to develop (A. Björklund, personal communication), and the maturation of electrophysiologic responses to nigral grafts reinnervating the striatum evolve over 8-9 months (Fisher et al., 1991). These examples, considered together with the evidence in the present study for the growth and remodeling of the regenerated retino$\mathrm{SC}$ connections, suggest that a prolonged period of axon-terminal and synaptic plasticity is possible in the injured CNS of adult mammals.

\section{Specificity of the regenerated $R G C$ axons and terminals}

While it is not known if the deployment of the RGC axons in the SCs of these hamsters is retinotopic, many of the charac- teristics that are gradually acquired by the regenerated axons that penetrate the SC resembled those of normal retino-collicular conncctions. These include the selective extension and arborization of the regenerated RGC axons in the SGS and SO, as well as a small growth into the SGI (Carter et al., 1991a); the overall ultrastructural appearance of the regenerated axon terminals and their synapses; the presence of smaller terminals in the superficial SGS than in the SO; the formation of synapses on appropriate proportions of dendritic shafts and spines at all limes examined; and normal proportions of synapses with the class of SC neurons identifiable by their content of synaptic vesicles. These features of the regenerated retino-SC connections suggest that the growth and differentiation of these axons may be under the influence of specific axon-target interactions. The demonstration that such preferences persist during the protracted phase of tectal reinnervation raises the possibility that other CNS connections may be gradually restored by axons that regenerate to the vicinity of their neuronal targets or by interneurons that are close to each other. As new strategies for the enhancement of RGC survival and growth are developed (Kapfhammer et al., 1992; Mansour-Robaey et al., 1992), it will important to determine if such reinnervation preferences continue to prevail.

\section{References}

Bernstein JJ, Bernstein ME (1971) Axonal regeneration and formation of synapses proximal to the site of lesion following hemisection of the rat spinal cord. Exp Neurol 30:336-351.

Carter DA (1991) Differentiation of regenerated retinal ganglion cell connections in the superior colliculus of adult hamsters. PhD thesis, McGill University.

Carter DA, Bray GM, Aguayo AJ (1989) Regenerated retinal ganglion cell axons can form well-differentiated retinal ganglion cell axons in the superior colliculus of adult hamsters. J Neurosci 9:4042-4050.

Carter DA, Aguayo AJ, Bray GM (1991a) Retinal ganglion cell terminals in the hamster superior colliculus: an ultrastructural study. $\mathbf{J}$ Comp Neurol 311:97-107.

Carter DA, Bray GM, Aguayo AJ (1991b) Patterns of the arborizations made by retinal ganglion cell axons regenerating into the superior colliculus of adult hamsters. Soc Neurosci Abstr 17:568.

David S, Bouchard C, Tsatas O, Giftochristos N (1990) Macrophages can modify the nonpermissive nature of the adult mammalian central nervous system. Neuron 5:463-469.

Duffy MT, Liebich DR, Garner LK, Hawrych A, Simpson J, Davis BM (1992) Axonal sprouting and frank regeneration in the lizard tail spinal cord: correlation between changes in synaptic circuitry and axonal growth. J Comp Neurol 316:363-374.

Fisher IJ, Young SJ, Tepper JM, Groves PM, Gage FH (1991) Electrophysiological characteristics of cells within mesencephalon suspension grafts. Neuroscience 40:109-122.

Garofalo L, Ribeiro-da-Silva $\Lambda$, Cuello $\Lambda C$ (1992) Nerve growth factor-induced synaptogenesis and hypertrophy of cortical cholinergic terminals. Proc Natl Acad Sci USA 89:2639-2643.

Gibbs RB, Harris EW, Cotman CW (1985) Replacement of damaged cortical projections by homotypic transplants of entorhinal cortex. $\mathbf{J}$ Comp Neurol 237:47-64.

Hayes W, Meyer R (1988) Normal numbers of retinotectal synapses during the activity-sensitive period of optic regeneration in goldfish: HRP-EM evidence implicating synapse rearrangement and collateral elimination during map refinement. J Neurosci 9:1400-1413.

Heumann R, Korsching S, Bandtlow C, Thoenen H (1987) Changes in nerve growth factor synthesis in non-neuronal cells in response to sciatic nerve transection. J Cell Biol 104:1623-1631.

Hillman DE, Chen S (1985) Plasticity in the size and presynaptic and postsynaptic membrane specializations. In: Synaptic plasticity (Cotman CW, ed), pp 39-76. New York: Guilford.

Houser CR, Lee M, Vaughn JE (1983) Immunocytochemical localization of glutanic acid decarboxylase on normal and deafferented superior colliculus: evidence for reorganization of gamma-aminobutyric acid synapses. J Neurosci 3:2030-2042. 
Jones EG (1983) The structural basis of neurobiology, pp 305-315. New York: Elsevier.

Kalil R, Dubin M, Scott G, Stark L (1986) Elimination of action potentials blocks the structural development of retinogeniculate synapses. Nature 323:156-158.

Kapfhammer JP, Schwab ME, Schneider GE (1992) Antibody neutralization of neurite growth inhibitors from oligodendrocytes results in expanded pattern of postnatally sprouting retinocollicular axons. J Neurosci 12:2112-2119.

Keirstead SA, Rasminsky M, Fukuda Y, Carter DA, Aguayo AJ, VidalSanz M (1989) Electrophysiologic responses in hamster superior colliculus evoked by regenerating retinal axons. Science 246:255-257.

Lund R (1969) Synaptic patterns of the superficial layers of the superior colliculus of the rat. J Comp Neurol 135:179-208.

Mansour-Robaey S, Bray GM, Aguayo AJ (1992) In vivo effects of brain-derived neurotrophic factor (BDNF) and injury on the survival of axotomized retinal ganglion cells (RGCs) in adult rats. Mol Cell Biol 3:333.

Matthews D, Cotman C, Lynch G (1976) An electron microscopic study of lesion-induced synaptogenesis in the dentate gyrus of the adult rat. II. Reappearance of morphologically normal synaptic contacts. Brain Res 115:23-41.

Meyer M, Matsuoka I, Wetmore C, Olson L, Thoenen H (1992) Enhanced synthesis of brain-derived neurotrophic factor in the lesioned peripheral nerve: different mechanisms are responsible for the regulation of BDNF and NGF mRNA. J Cell Biol 1 19:45-54.

Mize RR, Spencer RF, Sterling P (1982) Two types of GABA-accumulating neurons in the superficial gray layer of the cat superior colliculus. J Comp Neurol 206:180-192.

Murray M, Edwards M (1982) A quantitative study of the reinnervation of the goldfish optic tectum following optic nerve crush. J Comp Neurol 209:363-373.

Murray M, Sharma S, Edwards M (1982) Target regulation of synaptic number in the compressed retinotectal projection of goldfish. J Comp Neurol 209:374-385.

Murray M, Wu LF, Goldberger ME (1987) Spared root deafferentation of cat spinal cord: anatomical recovery. In: Effects of injury on trigeminal and spinal somatosensory systems (Pubols LM, Sessle BJ, eds), pp 261-271. New York: Liss.
Purves D, Lichtman JW (1984) Principles of neural development, pp 301-308. Sunderland, MA: Sinauer.

Radel J, Yoon M (1985) Time-course of ultra-structural changes in regenerated optic fiber terminals of goldfish. Brain Res 342:168-171.

Raisman G (1969) Neuronal plasticity in the septal nuclei of the adult rat. Brain Res 14:25-48.

Raisman G, Field PM (1973) A quantitative investigation of the development of collateral reinnervation after partial deafferentation of the septal nuclei. Brain Res 50:241-264.

Ramirez JJ, Jhaveri S, Hahm J, Schneider GE (1990) Maturation of projections from occipital cortex to the ventrolateral geniculate and superior colliculus in postnatal hamsters. Dev Brain Res 55:1-9.

Sotelo C (1975) Synaptic remodelling in mutants and experimental animals. In: Aspects of neural plasticity (Vital-Durand F, Jeannerod M, eds), pp 167-190. Paris: INSERM.

Steward O, Vinsant S, Davis L (1988) The process of reinnervation in the dentate gyrus of adult rats: an ultrastructural study of changes in presynaptic terminals as a result of sprouting. J Comp Neurol 267: 203-210.

Streit P, Knecht E, Reubi J-C, Hunt SP, Cuenod M (1978) GABAspecific presynaptic dendrites in pigcon optic tectum: a high resolution autoradiographic study. Brain Res 149:204-210.

Valverde $F$ (1973) The neuropil in superficial layers of the superior colliculus of the mouse: a correlated Golgi and electron microscopic study. Z Anat Entwicklungsgesch 142:117-147.

Vidal-Sanz M, Bray GM, Villegas-Pérez MP, Thanos S, Aguayo AJ (1987) Axonal regeneration and synapse formation in the superior colliculus by retinal ganglion cells in the adult rat. J Neurosci 7:28942909.

Vidal-Sanz M, Bray GM, Aguayo AJ (1991) Regenerated synapses persist in the superior colliculus after the regrowth of retinal ganglion cell axons. J Neurocytol 20:940-952.

Villegas-Pérez MP, Vidal-Sanz M, Bray GM, Aguayo AJ (1988) Influences of peripheral nerve grafts on the survival and regrowth of axotomized retinal ganglion cells in adult rats. J Neurosci 8:265-280.

Zwimpfer TZ, Aguayo AJ, Bray GM (1992) Synapse formation and preferential distribution in the granule cell layer by regenerating retinal ganglion cell axons guided to the cerebellum of adult hamsters. $\mathbf{J}$ Neurosci 12:1144-1159. 